\title{
Chemicals Inducing Seed Germination and Early Seedling Development
}

\author{
Emmanuelle Villedieu-Percheron, Mathilde Lachia, Pierre M. J. Jung, Claudio Screpanti, \\ Raymonde Fonné-Pfister, Sebastian Wendeborn, Didier Zurwerra, and Alain De Mesmaeker*
}

\begin{abstract}
Seed germination and early seedling development are essential events in the plant life cycle that are controlled largely by the interplay and cross-talk between several plant hormones. Recently, major progress has been achieved in the elucidation at the molecular level of the signalling of these phytohormones. In this review, we summarise the data for the most promising classes of compounds, which could find potential agronomic applications for promoting seed germination and early seedling development even under abiotic stress conditions. Structural modifications of plant hormones are required to improve their biological performance and their specificity to allow commercial application.
\end{abstract}

Keywords: Brassinosteroids · Gibberellins · Karrikins · Seed germination · Strigolactones

\section{Introduction}

Most global agricultural production relies on a rather limited number of annual crops used for food, feed and fibre production. ${ }^{[1]}$ These crops depend primarily on seeds for regeneration. For this reason, seeds play a pivotal role in agricultural production and consequently must possess a series of physiological and agronomical traits in order to ensure successful germination and seedling establishment. The properties that determine the potential for a rapid, uniform emergence and development of seedlings under a wide range of field conditions are described as seed vigour. ${ }^{[2]} \mathrm{A}$ larger number of studies have pointed out the link between seed vigour and field performance, particularly with respect to yield in several crops. [3]

Recent advances in seed science have shown how germination and seedling development are complex traits involving numerous genes regulated by multiple molecules that ultimately influence the seed vigour. ${ }^{[4]}$ These latest observations have opened the way to investigate chemicals

\footnotetext{
${ }^{*}$ Correspondence: Dr. A. De Mesmaeker Syngenta Crop Protection Muenchwilen AG Schaffhauserstrasse

$\mathrm{CH}-4332$ Stein

Tel.: +4162 8660268

E-mail: alain.de_mesmaeker@syngenta.com
}

involved in the regulation of seed germination and early seedling development.

In this review we summarise the major chemical classes that improve seed germination and early seedling development. The application and optimisation of synthetic molecules that affect seed germination and plant establishment open the possibility to improve seed vigour and crop production, particularly under stressful environments (abiotic stress). This constitutes a promising approach in the context of climate change and an ever-increasing population.

\section{Biology of Germination and Early Seedling Development}

Seeds consist of preformed tissues containing all of the genetic information that will determine germination and plant establishment. Germination, the first step in the crop cycle, represents a strong biological commitment for mature seeds. In order to achieve successful germination and crop establishment, seeds have developed the ability and tools to sense the environment. [5a] The time of the year is probably detected by temperature changes or wavelength sensing. The seeds have to evaluate if they are in the soil (nitrate sensing) and if so how deep they are buried (oxygen level sensing). Soil perturbation and plant canopy are detected by light intensity and quality, respectively.[5a,b] Finally, water and microorganism sensing are two other key elements that can influence germination. ${ }^{[5 a]}$

Crop seeds should have a low susceptibility to soil-born pathogens as well as a low dormancy coupled to a high longevity. Dormancy prevents premature germination and allows seeds to survive until good environmental conditions are available to support not only germination but also seedling establishment. For most of the seeds, dormancy is released by imbibition associated with a rapid decline in existing abscisic acid (ABA) content mainly through catabolism of the hormone by a cytochrome $\mathrm{P} 450$ monooxygenase-catalysed hydroxylation. ${ }^{[4 c, 6]}$

The germination process sensu stricto stops when the embryonic radicle protrudes and includes three phases where movement of water is involved. ${ }^{[5 a, 7]}$ The first phase corresponds to rapid penetration by water into the dry seed, driven solely by the difference in water potential between the dry seed and the soil or its close environment. Water influx is kept constant during the second phase in which membrane, DNA and protein are repaired. During this phase antioxidant and detoxification reactions are of great importance. Flavonoids and vitamins, as well as enzymatic or non-enzymatic ROS scavengers, are required to protect the embryo cells. The turnover and recycling of important cellular components is also activated. Mitochondrial respiration is restarted and storage proteins, lipids and mRNAs are recycled to provide essential molecules like amino acids, vitamins, nitrogen and sulphur for de novo synthesis, as seeds are a closed environment until radicle protrusion. ${ }^{[8]}$ Finally the transcription and translation machineries are fully activated and water flux increases again by completion of germination. Germination can be described as the result of two opposing driving forces: i) positive forces promoting embryo growth; and ii) restrictive forces due to the constraints of all layers surrounding the embryonic growing tissues. Endosperm weakening is an essential step which regulates the speed 
at which germination completion happens. This requires enzymes that modify cell walls. ${ }^{[5 a, 8 a, b]}$

Germination is a complex trait involving many genes. These genes are spatiotemporal tightly controlled by multiple molecules. ${ }^{[4 b, 9]}$ Historically, a special emphasis has been given to the balance between abscisic acid (ABA) and gibberellin (GA) but other phytohormones (brassinosteroids, auxin, ethylene, cytokinins, salicylic acid, jasmonic acid, and strigolactones) as well as some specific signalling compounds as karrikins, $\mathrm{NO}$ and reactive oxygen species are key components in the regulation of dormancy and germination. $[4,10,11 \mathrm{c}, \mathrm{d}, \mathrm{e}]$

In the following paragraphs we will provide an overview of the current knowledge of the role of most important chemical classes in controlling the germination and early seedling development and their possible applications in agriculture.

\section{Gibberellins (GA)}

Gibberellins are a family of natural tetracyclic diterpenes displaying various growth regulatory activities in seeds and in plants. Gibberellins are pleotropic phytohormones which affect numerous plant development processes from seed germination, leaf expansion, stem elongation, flower initiation and development, fruit development. ${ }^{[11]}$ There are 136 natural gibberellins which have been identified in plants and fungi. Around 100 of them are present in the plant kingdom, although each plant species contains typically around 10 different members of the group gibberellins. There are only a few gibberellins that stimulate seed germination in a wide range of plant species. ${ }^{[11 \mathrm{c}, \mathrm{d}, \mathrm{e}]}$ The structure of the gibberellins that strongly stimulate seed germination is species dependent. ${ }^{[12,13]}$
In this review, we focus on the role of gibberellins in seed germination. Gibberellic acid $\mathrm{GA}_{3}$, which is manufactured by an efficient fermentation process, is the most readily accessible gibberellin. [11b] Consequently, numerous studies reported in the literature refer to $\mathrm{GA}_{3}$ and a few closely related derivatives.

One of the key features in seed germination is the cross-talk between abscisic acid (ABA) and gibberellins (GA). ABA is a positive regulator of dormancy induction and a negative regulator of seed germination. ${ }^{[11 c, d, e, 14]}$ In contrast, GA release dormancy, promote germination and counteract ABA effects in seed.

In many species the biosynthesis of gibberellins in developing seeds leads to the accumulation and storage of bio-inactive precursors of GA (probably the ent-kaurene) and/or of bioactive gibberellins (for example $\mathrm{GA}_{3}, \mathrm{GA}_{1}, \mathrm{GA}_{4}$ in Fig. 1). ${ }^{[15]}$ In Arabidopsis, for example, the bioactive gibberellins accumulate prior to radicle protrusion within the embryo in two separated locations. ${ }^{[15 b, 16]}$ Gibberellins increase the growth potential of the embryo and they trigger the weakening of the tissues surrounding the radicle in order to overcome the mechanical constrains imposed by the seed-covering layers. ${ }^{[17]}$ For example in tomato and in Arabidopsis, weakening of the micropylar endosperm is required for germination and is achieved by cell-wall hydrolysis catalysed by the hydrolases that are induced by GA.[16,17] Indeed, several GA-inducible genes related to cell-wall loosening have been identified in tomato seeds, including those encoding endo- $\beta$-mannonase, xyloglucan endotransglycosylase/hydrolase, expansin and $\beta$-1,3-glucanase and chitinase, some of which are expressed specifically in the micropylar endosperm cap around the radicle. ${ }^{[16]}$

Mutant seeds deficient in GA biosyn-

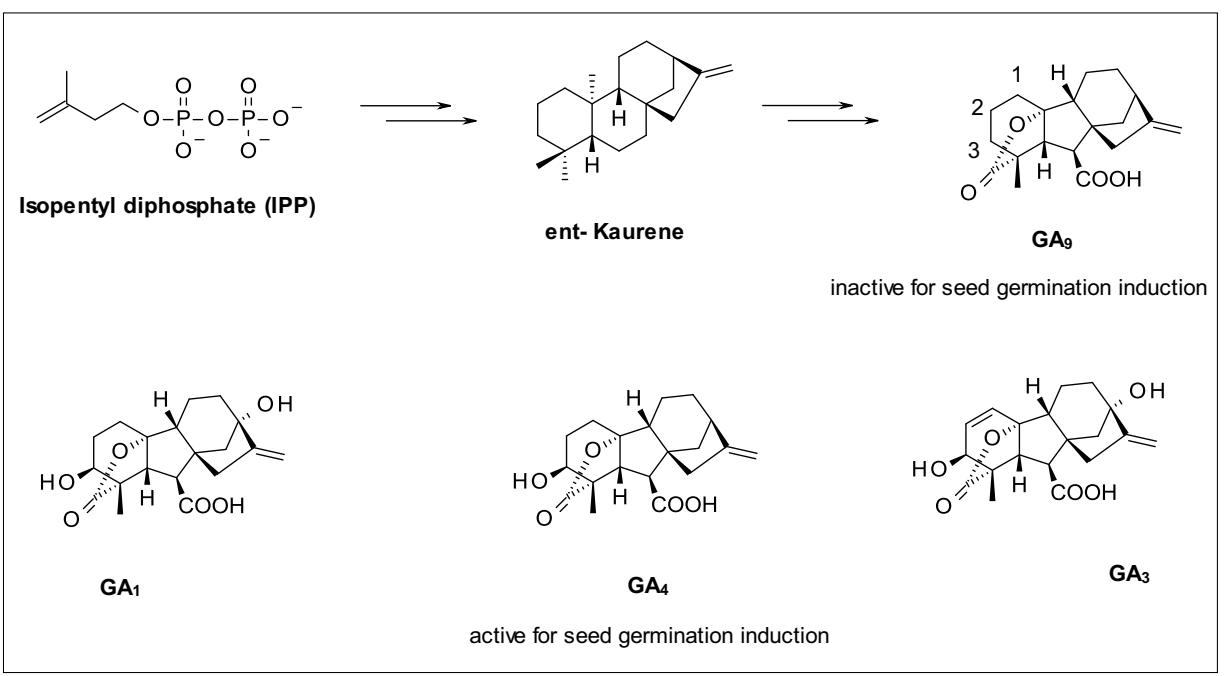

Fig.1. Biosynthesis of gibberellins and some of the bioactive forms responsible for seed germination stimulation. thesis have shown to be absolutely dependent for their germination on exogenous GA added to the imbibition solution, underlining the essential roles of gibberellins in promoting and increasing the rate of seed germination. ${ }^{[18]}$ The release from photo dormancy and the stimulation of germination of many species of light requiring seeds are regulated by phytochrome. ${ }^{[15 a, 19]}$ Red light up-regulates the biosynthesis of the bioactive gibberellins $\mathrm{GA}_{1}$ and $\mathrm{GA}_{4}$ through the induction of the corresponding genes in the germination of Arabidopsis and lettuce seeds. ${ }^{[15 a, 16 a]}$ Red light induces the expression of the genes responsible for the activation of bio-inactive gibberellins through $3 \beta$-hydroxylation by GA $3 \beta$-hydroxylases. Moreover, the deactivation of gibberellins by hydroxylation at $\mathrm{C} 2$ (GA-degrading enzymes) is suppressed in lettuce by red light.[20] Consequently, red light increases the level of bioactive GAs in germinating seeds by mediating de novo synthesis, by activation of inactive forms of GA and by reducing the degradation of the bioactive gibberellins. For example Nicotiana tabacum seeds are dependent on red light for their germination. Exogenous GA overcomes the need for red light and promotes seed germination in the dark. [17b] In addition, exogenous GA was shown to increase the rate of germination of various seed species, which do not require light. [11c] Seed germination promotion by cold treatment results also from an increased content of bioactive gibberellins due to an overexpression of the GA $3 \beta$-hydroxylases genes. ${ }^{[16 b]}$

The molecular mechanism of gibberellins perception at the receptor level is well understood: they stimulate seed germination by reducing the content of DELLA proteins. ${ }^{[21]}$ The signalling of gibberellins involves their binding to the nuclear GID1A receptor. High-resolution $\mathrm{X}$-ray diffraction structure was obtained for the ternary complexes GA3-GID1ADELLA and GA4-GID1A-DELLA from Arabidopsis thaliana. ${ }^{[22]}$ The core domain of GID1A offers a deep pocket for the binding of $\mathrm{GA}_{3} / \mathrm{GA}_{4}$, which induces a large movement of the $\mathrm{N}$-terminal extension of the protein (closing the lid) offering a new surface for interaction with DELLA proteins. The binding to DELLA proteins allows their recruitment by F-box proteins in an ubiquitin ligase SCF complex leading to polyubiquitinylation followed by degradation of the DELLA proteins by the $26 \mathrm{~S}$ proteasome. Through this mechanism, gibberellins stimulate the destruction of growth repressing DELLA proteins that bind to transcription factors and prevent them from function.

The commercial use of gibberellins for promoting seed germination is rather restricted due to the unfavourable changes 
in the phenotype of the resulting plants. ${ }^{[11]}$ Gibberellins stimulate stem elongation which leads to taller plants which are more susceptible to lodging. This unfavourable seedling phenotype is a severe limitation to the use of gibberellins for agronomical application. Interestingly, the potent seed germination inducers strigolactones and karrikins lead to seedling with largely unmodified phenotype (vide infra).

Substituted phthalimides have been shown to be as efficient as gibberelic acid $\mathrm{GA}_{3}$ in the promotion of the germination of dormant seeds in several species (Fig. 2). ${ }^{[23]}$ Among the three phthalimides investigated, compound AC-94377 is the most active one, coming very close or in some cases being even slightly superior to the stimulating efficiency of $\mathrm{GA}_{3}$, followed by AC-99,524 and AC-92,803, which is the least active derivative. The phthalimides act on the same seed species as $\mathrm{GA}_{3}$, suggesting that they have intrinsic gibberellin-like activity.

\section{Ethylene}

The biosynthesis of ethylene in seeds and its role in signalling are key processes for the germination of dormant and non-dormant seeds. ${ }^{[24]}$ Ethylene is biosynthesised in a two-step process from S-adenosylmethionine (SAM), which is converted into 1-aminocyclopropane-1-carboxylic acid (ACC) through catalysis by the enzyme ACC synthase (ACS) (Fig. 3). This cyclopropanation reaction is the rate-determining step in ethylene biosynthesis. ${ }^{[24,25]}$ The conversion of ACC into ethylene is catalysed by the ACC oxidase (ACO). ${ }^{[26]}$ It has been shown that during seed germination, ethylene promotes its own biosynthesis, for example in pea, by a positive feedback regulation of $P s-A C O 1$ transcripts. ${ }^{[24 \mathrm{~b}]}$ The potential roles of ethylene in breaking seed dormancy have been investigated. ${ }^{[27]}$

Ethylene promotes seed germination and acts as an antagonist of abscisic acid (ABA). Ethylene does not affect the ABA levels in seeds. However, ethylene counteracts the inhibitory effects of ABA on germination by interference with its signalling. ${ }^{[24,28]}$ The partial reversion of the ABA inhibitory effect on seed germination could be achieved by the addition of exogenous ethylene. Ethylene is suggested to be involved in weakening the endosperm cell walls required for a successful radicle protrusion. ${ }^{[24]}$ Owing to its physicochemical properties, ethylene diffuses freely across membranes and is able to reach its receptors without encountering major barriers. The signalling of ethylene is mediated through its receptors which are transmembrane protein dimers. In Arabidopsis thaliana, five receptors of ethylene have been characterised, ETR1, ETR2, ERS1, ERS2 and EIN4.[24,27] The binding of ethylene to its receptors leads to their inactivation and leaves the negative regulator CTR1 (a serine-threonine protein kinase acting as negative regulator of ethylene signalling) inactive as well. The inactive CTR1 leads to the progression of a MAP-kinase cascade and controls the positive regulator EIN2 and its transcription factors, which activate the transcription of ethylene-responsive genes. These events lead finally to the induction of the response to ethylene.[24,29]

Ethylene has been shown to play a role in improving seed germination under heat stress. Addition of exogenous ethylene, or of its precursor ACC, leads to the reversion of the thermo inhibition in some species as chickpea and lettuce seeds. ${ }^{[30]}$ Thermo inhibition is associated with the modulation of abscisic acid, gibberellin and ethylene biosynthesis. In Arabidopsis thaliana seeds high temperature was shown to stimulate abscisic acid synthesis and to repress gibberellin synthesis and gibberellin signalling through the action of ABA. [31] In addition to ACC, another ethylene precursor which is frequently used to perform

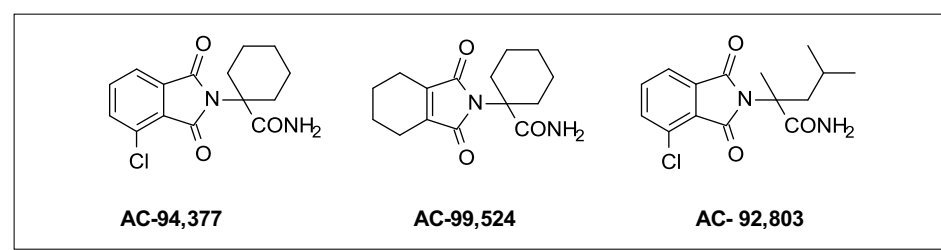

Fig. 2. Phthalimide derivatives displaying gibberellin-like seed germination stimulation activity.

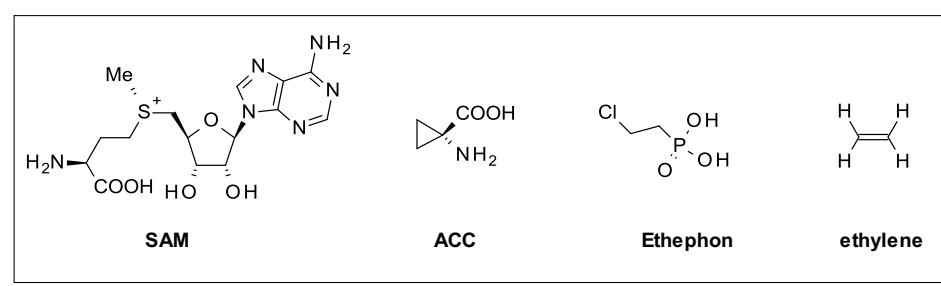

Fig. 3. Ethylene and ethylene precursors.

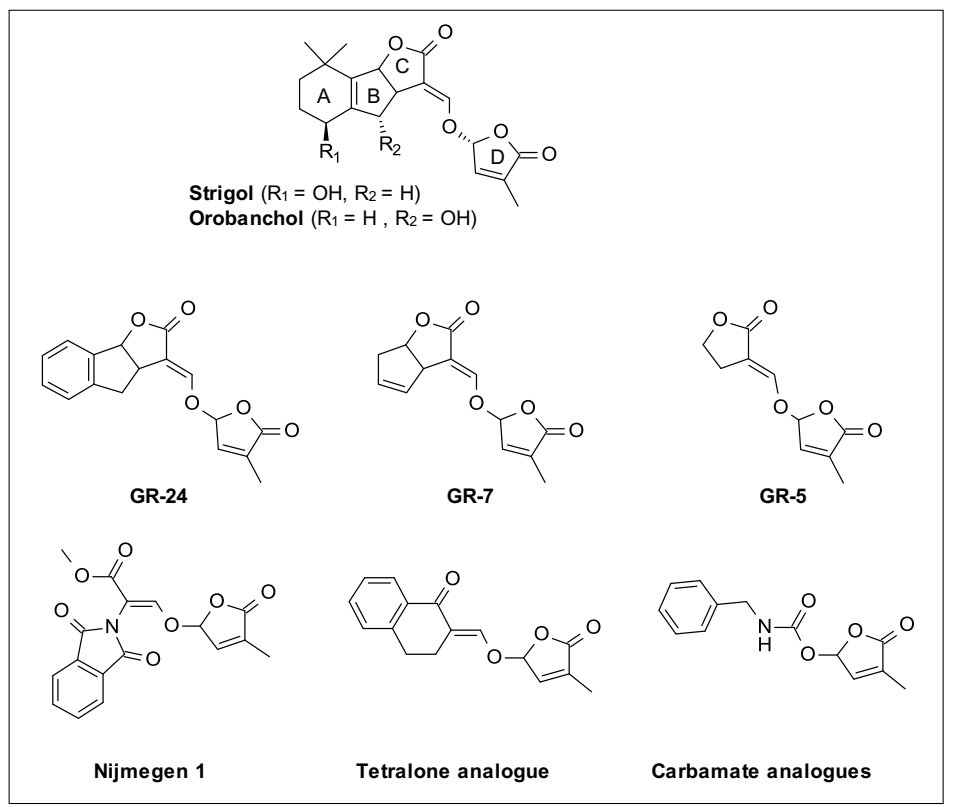

Fig. 4. Examples of strigolactones and of their synthetic analogues. 
parasitic weed control referred as suicide germination). Due to the relatively high complexity of the natural strigolactones, different research groups have entered this field, looking for cheaper and more accessible synthetic analogues of strigol. The preparation of simplified strigolactone analogues, namely GR-5, GR-7 and GR24 , was reported already in 1981, the last one is the most potent and is used in most studies as the synthetic standard for strigolactone derivatives (Fig. 4). ${ }^{[34]}$

Structurally, strigolactones are composed of a tricyclic lactone moiety (ABC rings) and a butenolide ring (D ring), linked by an enol ether. Extensive modification of the tricyclic lactone skeleton has been investigated and carbamate, phthalimide, ${ }^{[35]}$ lactone ${ }^{[36]}$ and saccharine ${ }^{[37]}$ have been reported to induce the germination of Striga and of Orobanche seeds, another parasitic weed causing damage to crops including sunflower. ${ }^{[38]}$ Unfortunately, field application of the synthetic strigolactone derivatives as potential suicidal germination inducers has been compromised by the instability of these compounds in the soil.[39]

The effect of strigolactones on seed germination was investigated with various species revealing that their activity is not restricted to parasitic weeds. It was already demonstrated in the 1980s that strigolactones can stimulate the germination of both monocot and dicot weeds as well as lettuce and tomato. ${ }^{[40]}$ GR-5 was the most potent strigolactone analogue tested, probably due to the better solubility of this small compound. More recently, it has been reported that strigolactones release the thermo inhibition of germination in the model plant Arabidopsis. ${ }^{[10 \mathrm{c}]}$ It was proposed that strigolactones prevent the accumulation of ABA during the thermo inhibition by regulating its biosynthesis. Strigolactones were also found to stimulate GA accumulation. In parasitic weeds, a similar mode of action was proposed, although cytokinins were also affected. Further evidence of the cross-talk between strigolactones and ABA was given when it was observed that

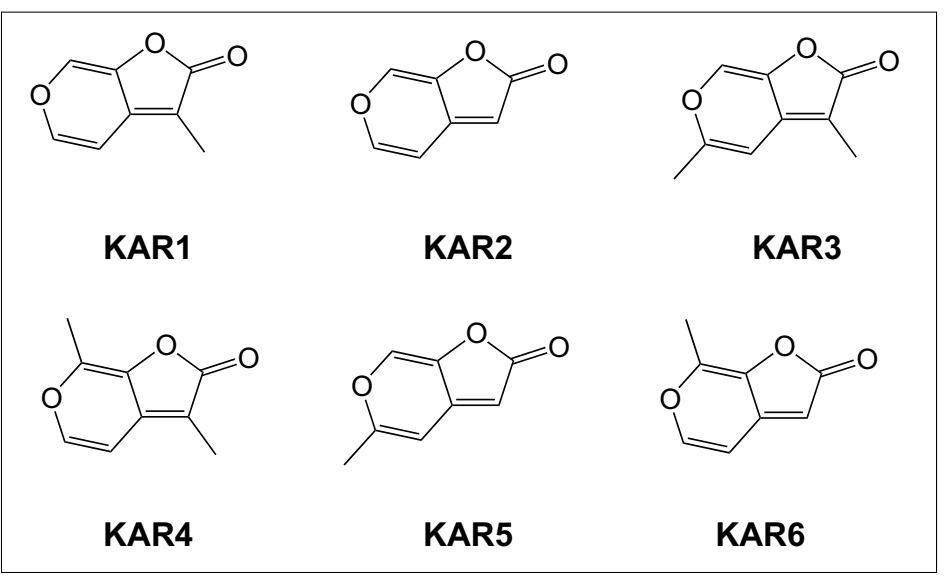

in parasitic weeds Phelipanche ramosa, strigolactones induce the expression of ABA 8'-hydroxylase, a key enzyme in the metabolism of ABA. [41]

Recently, the role of strigolactones not only in the rhizosphere but also in plants has been uncovered. In 2005, strigolactones were identified as very potent signalling molecules exuded by plant roots inducing hyphal branching of arbuscular mycorrhiza (AM fungi), leading to a mutually beneficial symbiotic interaction between plant roots and the AM fungi, which favour acquisition of nutrients and water from the soil. ${ }^{[42]}$ A few years later, strigolactones were identified as the latest discovered phytohormones involved in plant architecture. ${ }^{[43]}$ Since then, several major additional roles of strigolactones in plants have been identified, including their effect on controlling root and shoot architecture. ${ }^{[44]}$ The recent isolation and characterisation of the D14 protein involved in the perception of strigolactones, has unveiled similarities with the D14L/KAI2 protein involved in the perception of karrikins, both $\alpha / \beta$-hydrolases sharing a high level of homology. ${ }^{[45,46]}$ The high-resolution X-ray diffraction structures obtained for the D14 apo-protein and with the 5-hydroxy-3-methylbutenolide moiety, the hydrolysis product of the $\mathrm{D}$ ring bound in the active site, has provided some understanding of the mechanism of perception of strigolactones at the molecular level. The design of novel strigolactones analogues as potent seed germination inducers for various species including field crops should profit from the recent advances made in the elucidation of the roles of strigolactones in seeds and in plants. In addition, strigolactone derivatives might be very attractive for seed germination stimulation under abiotic stress conditions.

\section{Karrikins}

Smoke generated by the combustion of plants was already identified in the 1990s

Fig. 5. Karrikin isolated from smoke displaying seed germination stimulation activity. as a strong elicitor of seed germination. ${ }^{[47]}$ Initially a broad variety of seeds of plants growing in fire-prone environments were shown to be very sensitive to smoke for the stimulation of their germination. The species studied originated mainly from Australia, South Africa and California. ${ }^{[48]}$ However, it was demonstrated that seeds of various plant species arising also from environments which are not prone to fire respond very strongly to stimulants from smoke. ${ }^{[49]}$ Smoke-water, obtained by bubbling smoke from the combustion of plants through water, displays similar properties to smoke itself for seed germination induction and is more convenient for research and agronomical applications. Smoke and smoke-water elicit a striking increase in seed germination under field conditions in over 1200 species from 80 genera. ${ }^{[50]}$ Analysis of the molecules responsible for this very high seed germination stimulation is difficult due to the complexity of the mixture of compounds present in smoke-water. Among the 5000 compounds present in smoke-water, few of them are potent seed germination inducers, others display mainly no significant activity and in a few cases inhibitory activity. ${ }^{[51]}$ In addition, smoke-water contains some rather toxic compounds, in particular poly-aromatic oxidised derivatives displaying cytotoxic activity. ${ }^{[52]}$ Therefore, many efforts have been devoted in the 2000 s to isolate, purify and characterise the most active components of smoke-water. In 2004, two research groups have independently identified KAR1 as the major seed germination inducer of smoke-water produced by combustion of cellulose and of plants, respectively. ${ }^{[53]}$ The karrikin derivatives KAR1-KAR6 were isolated and purified from smoke-water and were also synthesised, thus facilitating the establishment of their structure-activity relationship (Fig. 5) . $.49 \mathrm{a}, 54]$

In general, KAR1 is the most abundant and the most active karrikin derivative present in smoke-water. Typically, KAR1 induces strong seed germination at very low concentrations $\left(10^{-6}-10^{-10} \mathrm{M}\right.$ for sensitive species). However, KAR2 is more potent than KAR1 for the induction of germination of Arabidopsis thaliana seeds. So far, only a rather restricted structure-activity relationship has been established for a few seeds species and karrikin derivatives and analogues. ${ }^{[49 a, 54]}$

Karrikins were recently shown to induce not only seed germination but also seedling growth/vigour in an increasingly broad variety of species. ${ }^{[5]}$ Interestingly, economically relevant species such as celery, lettuce, bean, rice, maize, carrot, tomato and onions, as well as several weed species, were shown to be very susceptible to treatment by KAR1 at very low con- 
centration. ${ }^{[55,56]}$ For various weeds, KAR1 showed a larger increase in the rate of seed germination compared to $\mathrm{GA}_{3}$ without displaying the unfavourable seedling morphology changes observed for gibberellins. ${ }^{[56]}$ These data are promising for the search of potential seed germination inducers for commercial applications as well as improving seedling growth/vigour, in particular under abiotic stress conditions. For example, maize seedlings arising from seeds treated with $10^{-7} \mathrm{M}$ solution of KAR1 develop significantly more and longer roots compared to untreated seeds. ${ }^{[55 \mathrm{~b}]}$ The effects of KAR1 on seeds go beyond germination and stimulate outgrowth of shoots and roots. KAR1 overcomes partially cold stress for the germination of tomato seeds at low concentration $\left(10^{-7} \mathrm{M}\right)$ offering potential applications for abiotic stress management for seed germination of crops at unfavourable soil temperature. ${ }^{[57]}$

The presence of a butenolide ring in the structure of karrikins and of strigolactones, as well as the similarities in their functions as seed germination stimulators has attracted much attention. ${ }^{[58]}$ Recently, the structural and functional relationships of these molecules were confirmed at the level of their mechanism of signal perception. [59] The structure of the karrikins binding protein (receptor) was elucidated by high-resolution X-ray diffraction of crystals of the Arabidopsis thaliana protein AtD14L/ KAI2.[45] KAR1 binds to a very closely related strigolactone protein D14 in rice, namely the D14-Like protein (AtD14L in Arabidopsis) also called KAI2. The X-ray diffraction structures of the AtD14L/KAI2 and D14 proteins are very similar. Only few hydrophobic residues in the binding site of these $\alpha / \beta$-hydrolases are slightly modified. Although both binding cavities in D14 and in AtD14L/KAI2 proteins containing the catalytic triad (Ser, His, Asp) are overall very similar, the hydrophobic pocket of AtD14L/KAI2 is somewhat smaller and accommodates more easily the more compact karrikin structure than the larger tetracyclic strigolactone moiety. ${ }_{[45,46]}$

The discrimination between the AtD14L/KAI2- and the AtD14-mediated signalling evolves during plant development through different transcription levels of the corresponding genes. During seed germination and seedling establishment, KAI2 and the karrikin-related signalling play a dominant role. In the later vegetative development the AtD14 receptor and the strigolactones signalling prevail.[59] Phylogenetic analysis of the karrikin and strigolactone receptors underlines their origin from ancestral genes present throughout the plant kingdom. ${ }^{[45 a]}$

Further evaluation of karrikin derivatives for potential commercial applications as seed germination inducers, in particular under abiotic stress conditions, combined with the recent progress made in the identification of their mode of action and perception at the molecular level will remain a field of intensive academic and industrial research.

\section{Brassinosteroids}

Brassinolide, isolated from rape pollen, is a plant steroid produced from campesterol through several oxidative steps. ${ }^{[60]}$ Brassinolide displays very potent plant growth promoting effects. Various analogues of brassinolide, including its direct biosynthetic precursor castasterone, have been synthesised and their plant growth promoting activity has been assessed.[61] These studies led to the establishment of a structure-activity relationship (SAR) for growth promotion which underlines the importance of the carbonyl function of the 7-membered ring lactone and of the hydroxyl groups in the side chain positions $\mathrm{C}(22), \mathrm{C}(23)$ as well as those in the $\mathrm{C}(2), \mathrm{C}(3)$ positions of the A-ring (Fig. 6). More recently, the molecular interactions of brassinolide with the ectodomain of the membrane bound leucine-rich repeat receptor kinase BRI1 was elucidated by X-ray crystallography of the brassinolide-protein complex. ${ }^{[62]}$ The interaction of the brassinosteroid with the ectodomain of BRI1 triggers a complex signalling cascade: the brassinolide-BRI1 complex allows interaction with the ectodomain of another membrane-bound kinase BAK1, a complex also resolved by X-ray crystallography, ${ }^{62 \mathrm{~d}]}$ and both kinases, BRI1 and BAK1, undergo cross phosphorylation of their cytoplasmic subunits, thereby transferring the hormonal signal into the cell. Through the involvement of other proteins in the signalling cascade, the activation of transcription factors is eventually achieved and specific genes in the cell nucleus are activated for transcription.

In most biological studies performed with brassinosteroids, four main classes of analogues have been used, which differ in the alkyl substitution of the side chain and the oxidation state of the B-ring: brassinolide, 24-epi-brassinosteroid and 28-homo-brassinosteroid, the latter two being synthetically accessible in five to seven steps from the steroid precursors ergosterol and stigmasterol, respectively, as well as their castasterone analogues. ${ }^{[63]}$

Brassinosteroids are mainly known for their growth-enhancing effects in a variety of crops at very low application rates, even under field conditions. ${ }^{[64]}$ The yield increase is particular strongly pronounced when the crop is grown under non-optimal conditions (heat-, cold-, water- and saltstress). Brassinosteroids have found some commercial applications despite their relatively high production costs. ${ }^{[65]}$

Seed germination and seedling establishment are also promoted by brassinosteroids, the effect usually being larger when germination occurs under abiotic stress conditions. For example seedling establishment of sorghum seeds exposed to drought stress simulation has been remarkably increased by treatment with 28-homo-brassinosteroid, thus demonstrating its stress mitigating effects during germination. [66] Positive effects of brassinosteroids were also observed on germination and seedling growth for maize, rice, cucumber, Arabidopsis thaliana and Brassica napus when seeds were germinated under salt- $(\mathrm{NaCl})$ stress or the seedlings were exposed to cold-, heat- or drought-stress conditions. ${ }^{[67]}$

The role of endogenous brassinosteroids and of their biosynthetic precursors during germination and seed growth has been studied in pea seeds by measuring their concentrations in various tissues.

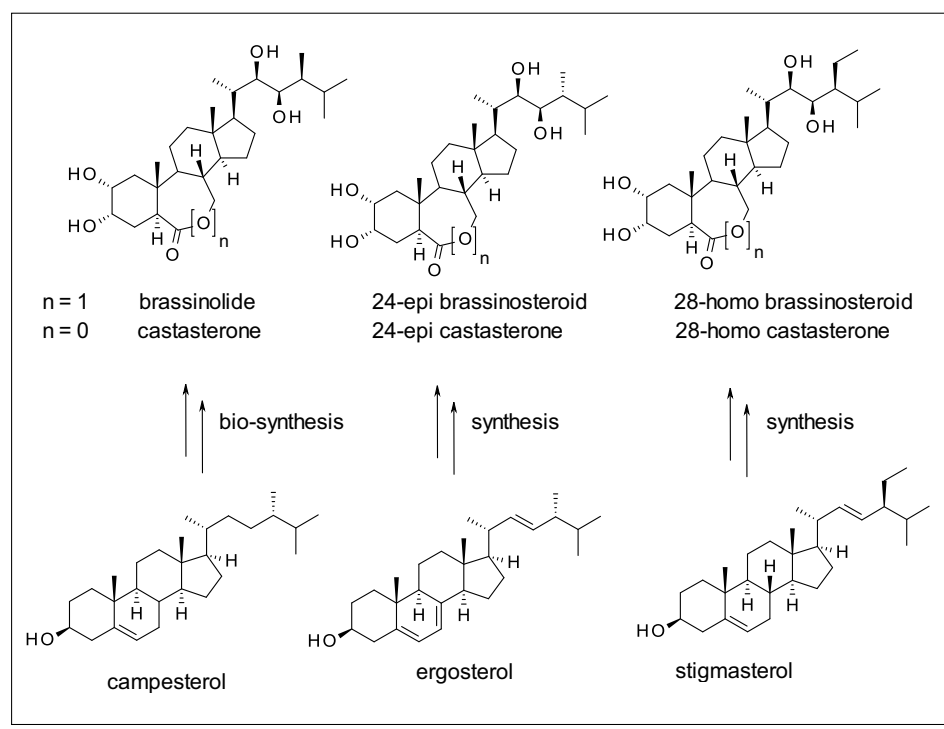

Fig. 6. Most commonly used brassinosteroids and their synthetic and biosynthetic precursors. 


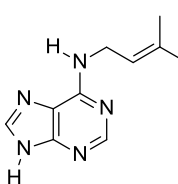

Isopentenyl adenine iP

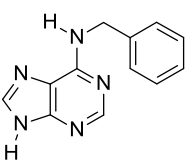

Benzyl adenine (BA)

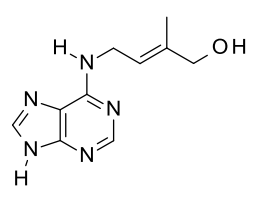

Trans zeatin tz

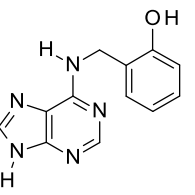

Ortho topolin (oT)
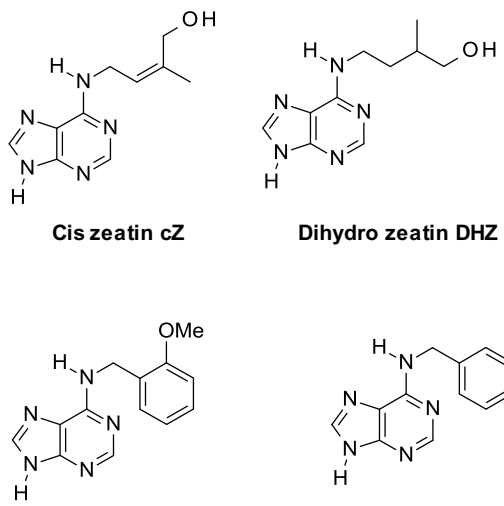

Ortho methoxytopolin (MeoT)$$
\text { Meta topolin (mT) }
$$

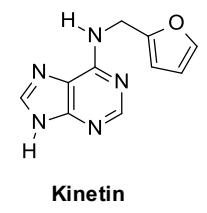

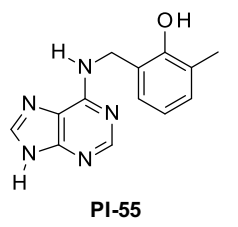

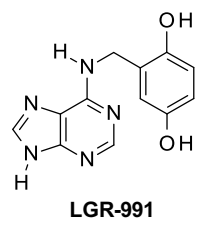

Fig. 7. Cytokinins and selected synthetic analogues.

Rapidly growing seeds have high brassinolide and castasterone concentrations, as well as high transcript levels of the C6-oxidases (CYP85A1 and CYP85A6), which are responsible for the $\mathrm{C}(6)$ oxidation of castasterone. ${ }^{[68]}$

Brassinosteroids significantly increase the rate of germination of the parasitic Orobanche minor seeds induced by strigolactones (strigol). ${ }^{69]}$ This synergistic effect of brassinosteroids might result from an increased permeability of the seed coat and membranes because brassinosteroids induce genes encoding for cell wall loosening enzymes. ${ }^{[70]}$

Although brassinosteroids promote seed germination and seedling growth, they are not an absolute requirement for these processes. Biosynthetic mutants, expressing lower levels of brassinosteroids undergo seed germination. ${ }^{[71]}$ In Arabidopsis brassinosteroids modulate the effects of the germination-suppressor abscisic acid (ABA) and the germination-promoter gibberellin (GA). Plant mutants deficient in gibberellin or insensitive to gibberellin show phenotypes with strongly reduced seed germination. 24-epi-brassinosteroid can partially rescue germination of those mutants. The mutants deficient in brassinosteroids or insensitive to brassinosteroids are more susceptible to inhibition of germination by ABA compared to wildtype. ${ }^{\text {[72] }}$ Therefore, brassinosteroids complement and can even partially substitute the germination promoting properties of gibberellin while reducing the germination inhibiting effect of ABA. In summary, brassinosteroids play key roles in the germination of a variety of seeds including those of major crops such as corn, rice and wheat. Their plant growth regulating roles are especially expressed during suboptimal growth conditions when the hormonal balance in plants is modified.

\section{Cytokinins}

Cytokinins are phytohormones that play key roles in cell regulation and various development processes. Cytokinins are derivatives of adenine with different substituents at the N6-position. They are divided in two sub-classes depending on the structure of the N6-side chain, namely the isoprenoid cytokinins (isopentenyl adenine IP, trans-zeatin $\mathrm{tZ}$, cis-zeatin $\mathrm{cZ}$, dihydro-zeatin DHZ) and the aromatic cytokinins (benzyl adenine BA, ortho-topolin oT, ortho-methoxytopolin MeoT, meta-methoxytopolin MemT, Fig. 7).[73] Cytokinins are present in all plant tissues with the isoprenoids being the most abundant. They are usually present in the lower $\mathrm{nM}$ range either in the free base form or as glucosidic, ribosidic and nucleotidic conjugates. ${ }^{[73]}$ The transport, and concentration of the biologically active cytokinins is regulated by their conjugation to ribose and glucose. ${ }^{[73]}$ While the glyco-conjugated analogues are biologically inactive, they are transported from the roots to the shoots. The interactions of the non-conjugated cytokinins, as well as urea-based synthetic cytokinin mimics with their histidine-kinase receptors in Arabidopsis thaliana, AHK4 have been investigated at the molecular level. ${ }^{[73 \mathrm{~d}]}$ Catabolism of cytokinins occurs though the oxidative cleavage of the N6-side-chain catalysed by cytokinin oxidase/dehydrogenase (CKO/CKX) which requires $\mathrm{FAD}$ as a co-factor, liberating adenine which displays no cytokinin activity. General roles of cytokinins involve induction of cell division, activation of gene expression and metabolic activity, retardation of leaf senescence, stimulation of shoot proliferation and, together with auxin, control of root formation. ${ }^{\text {[73-75] }}$

Seed germination of lettuce Lactuca sativa normally requires red light, but can occur with lower light intensity when a high concentration of cytokinin is present. [76] It was believed that at lower physiological levels cytokinins hardly play a role in seed germination. ${ }^{[76]}$ In addition, it was reported that cytokinins alone had no significant effect on the germination of lettuce and barley seeds in the dark. However, cytokinins or red light treatment were able to reverse the inhibiting effect of abscisic acid only if gibberellin was present. Gibberellin alone could not reverse the inhibiting effect of ABA on germination, even though this can be the case in other seed species. In other systems (chilled pear embryos) a combination of kinetin and GA is more efficient than either of them alone. [77] These seemingly confusing observations can be explained by cytokinins acting in a permissive role on germination in the interplay of GA (promoting seed germination) and ABA (inhibiting seed germination). ${ }^{[77,78]}$ The above-mentioned results, for the most part obtained in studies with exogenously applied phytohormones, were questioned when the use of loss-offunction mutants for the three Arabidopsis thaliana sensor histidine kinases, AHK2, AHK3 and CRE1/AHK4, the known cytokinin receptors, demonstrated that the corresponding mutant Arabidopsis thaliana seeds undergo more rapid germination, display a reduced requirement for light and a decreased far-red light sensitivity compared to the wild-type seeds. ${ }^{[79]}$ The results obtained with Arabidopsis mutants were confirmed by the use of cytokinin antago-

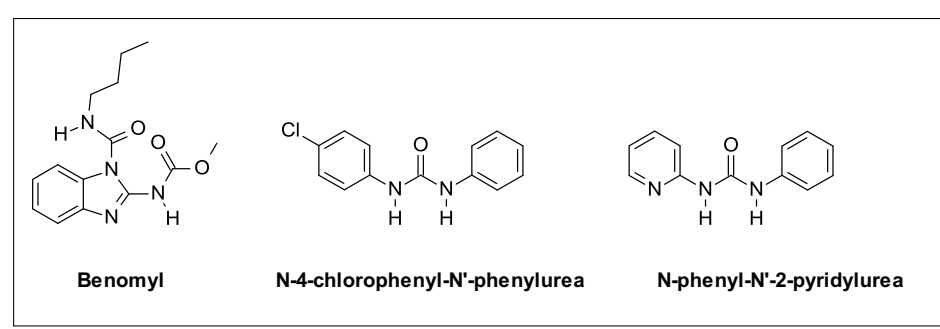

Fig. 8. Cytokinins agonists/ antagonists. 
nists, PI-55 and LGR-991 (Fig. 7), which are both closely related substituted benzyl adenine derivatives. ${ }^{[80,81]}$ PI-55 and LGR991 blocked cytokinin action via receptor inhibition and increased the rate of wildtype Arabidopsis seeds in a dose response fashion by a factor 2-3 (1-10 nM PI-55 or LGR-991). ${ }^{[80,81]}$ Recent data linked the antagonistic interplay between cytokinins and ABA to the bZIP transcription factor ABI5, which expression is induced by ABA and blocked by the cytokinins. ${ }^{[82]}$

Structures with cytokinin-like properties (potentially cytokinin agonists or antagonists) inducing germination were reported earlier albeit with much lower potency compared to LGR-991 and PI55. Benzimidazole-derived fungicides (for example benomyl, Fig. 8) stimulated the germination of celery seeds in the presence of gibberellins. ${ }^{\text {[83a] }}$ Celery seeds require cytokinins for their germination. ${ }^{[83 a]}$ 4-Substituted-2-methylpyrrolo[2,3-d] pyrimidines and N9-substituted benzyl adenine derivatives also showed induction of germination of lettuce similar to benzyl adenine itself. ${ }^{[83 \mathrm{~b}, 84]}$ Among the urea-type cytokinin analogues, substituted diphenyl ureas and pyridyl-phenyl ureas showed full germination induction of lettuce seeds at rather low concentration $\left(5.10^{-5} \mathrm{M}\right)$ than observed for kinetin and cytokinins. ${ }^{[85]}$ Urea, thiourea and methylurea exhibited only some control of germination if applied at higher concentration $\left(10^{-4}-10^{-2}\right.$ M). An inhibiting effect of germination was observed if the concentration was increased up to $1 \mathrm{M}$. ${ }^{[85]}$

In conclusion, significant data support the germination-promoting ability of cytokinins and cytokinin analogues. However, as cytokinin signalling loss-of-function mutants of Arabidopsis thaliana germinate more readily than the wild-type, cytokinin signalling might promote other events regulating seed germination which are not yet fully understood.

\section{Ascorbic Acid, Nitrogen Oxide (NO), Nitrite $\left(\mathrm{NO}_{2}{ }^{-}\right)$, Nitrate $\left(\mathrm{NO}_{3}{ }^{-}\right)$}

Ascorbic acid and small inorganic chemicals are also involved in seed germination. However, the cellular basis of their
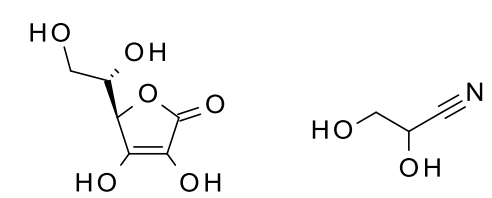

L- Ascorbic acid

Glyceronitrile

Fig. 9. Ascorbic acid and glyceronitrile are seed germination stimulators. mechanism is not yet fully understood, and seems to be species dependent.

Ascorbic acid (vitamin C, Fig. 9) is a strong antioxidant, a potential inhibitor of reactive oxygen species (ROS) production and increases plant resistance to stress. ${ }^{[86]}$ Therefore, ascorbic acid plays an important role in seed germination under stress conditions. ${ }^{[87]}$ It has been shown that ascorbic acid increases resistance to salt stress and has a beneficial effect, for example, on fenugreek (Trigonella foenum-graecum) seed germination. ${ }^{[88]}$ However, pre-treatment with ascorbic acid under normal conditions (unstressed) had no effect on germination. The inductive role of ascorbic acid in seed germination is largely related to its antioxidant activity. Ascorbic acid is also a cofactor for several enzymes, in particular key enzymes required for the biosynthesis of phytohormones, such as 1-aminocyclopropane-1-carboxylate oxidase (ACO) involved in ethylene biosynthesis, or gibberellin 20-oxidase. ${ }^{[89,90]}$ Consequently, ascorbic acid could have several additional effects on seed germination through its indirect influence on the levels of ethylene and gibberellins and in mediating the antagonism between ABA and GA. [89,90]

Several nitrogen-containing compounds such as nitrogen oxide (NO), nitrite $\left(\mathrm{NO}_{2}^{-}\right)$, nitrate $\left(\mathrm{NO}_{3}^{-}\right)$, nitrogen dioxide $\left(\mathrm{N}_{2} \mathrm{O}_{4}\right)$, ammonium $\left(\mathrm{NH}_{4}^{+}\right)$, azide $\left(\mathrm{N}_{3}^{-}\right)$and cyanide $\left(\mathrm{CN}^{-}\right)$promote dormancy breaking and seed germination in many plant species. ${ }^{[11 e]}$ The elucidation of the active entities is complicated by the inter-conversion of these nitrogen-containing compounds. However, these compounds are acting as potential sources of $\mathrm{NO}$ and/or act through mechanisms similar to the ones involved in NO mode of action. These sources of nitric oxide are usually produced in the soil by microorganisms or excreted by all plants and animals. Nitric oxide is also produced enzymatically in plant mitochondria primarily via nitrate reductase from nitrite and nitrate. Several studies used synthetic precursors of NO to investigate its actions on seeds and plants. For example, application of a NO donor such as SNP (sodium nitroprusside, $\mathrm{Na}_{2}\left[\mathrm{Fe}(\mathrm{CN})_{5} \mathrm{NO}\right]$ ) removed dormancy in Arabidopsis. [91] NO is required for the transcription of the GA3ox1 and GA3ox2 genes which lead to two key biosynthetic enzymes for active gibberellins. NO coordinates a reduction in ABA-imposed dormancy with the onset of gibberellin-stimulated germination. ${ }^{[92]}$ Indeed, nitrate treatment of dormant Arabidopsis seeds led to a relief of dormancy and to the decrease in $\mathrm{ABA}$ content by stimulation of its oxidative catabolism and by prevention of its de novo synthesis. ${ }^{[93]}$

The alleviation of seed dormancy by treatment with SNP relies on the release of $\mathrm{NO}$ and of cyanide. ${ }^{[91]} \mathrm{HCN}$ is produced in cyanogenic and non-cyanogenic species upon hydrolysis of cyanogens (cyanolipids, cyanoglycosides and cyanohydrins). ${ }^{\text {[94] }}$ Seeds evolve HCN during the early periods of water imbibition (pre-germination period). However, HCN release decreases and finally stops with the start of germination. ${ }^{[94]}$ Treatment of seeds with gaseous $\mathrm{HCN}$, potassium ferrocyanide, potassium ferricyanide, or SNP (cyanide precursors) allowed dormancy release of Arabidopsis seeds. ${ }^{[94,95]}$ Smoke of burning plant material produces, amongst thousands of other molecules, the cyanohydrin glyceronitrile, which in the presence of water releases cyanide, which in turn stimulates seed germination of various fire-responsive species.[96]

\section{Abscisic Acid (ABA) Biosynthesis Inhibitors}

Abscisic acid (ABA) is one of the key phytohormones derived from carotenoids and is involved in seed dormancy and germination.[6a,11d,97] The essential regulatory role of abscisic acid, namely inducing and maintaining dormancy and repressing germination, is directly linked to the level of its expression in the seed. The application of exogenous ABA on the seed or the increase in the concentration of ABA within the seed by overexpression of the genes involved in its biosynthesis induces seed dormancy and inhibits seed germination. In contrast, reduction of the level of ABA in seed by mutation of biosynthetic genes or by treatment with exogenous molecules interfering with ABA biosynthesis, results in the alleviation of seed dormancy and/or in an increase of germination. ${ }^{[98]}$ We present here different classes of compounds able to stimulate seed germination, either by inter-
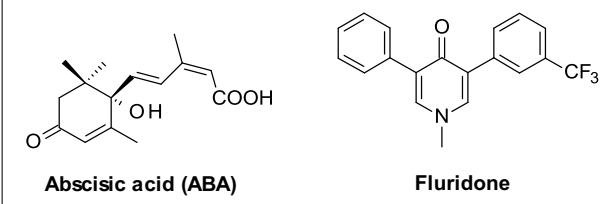

Fig. 10.

Compounds used to decrease ABA level through phytoene desaturase inhibition.

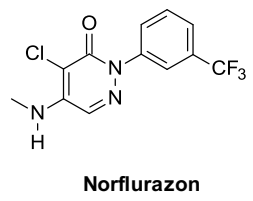


fering with ABA-biosynthesis or through direct antagonistic competition with ABA binding at its biochemical target.

Fluridone and norflurazon are bleaching herbicides which act by inhibition of carotenoid biosynthesis in plants (Fig. 10). The molecular target of these herbicides is the phytoene desaturase, an enzyme involved in the conversion of phytoene to $\xi$-carotene, which is further transformed into $\beta$-carotene. ${ }^{[99,100]}$ Fluridone and norflurazon have been used to control the level of ABA in seeds because phytoene desaturase is involved in the biosynthesis of ABA as one of the molecules resulting from the transformation of $\beta$-carotene. Fluridone and norflurazon are still currently used in studies investigating the roles of ABA in seed germination but they have strong side effects during plant growth due to their herbicidal mode of action depleting carotenoids biosynthesis, which leads to strong phytotoxicity (bleaching).

Norflurazon and fluridone stimulate the relief of dormancy and the germination of seed and embryo in many plant species under favourable conditions as well as under abiotic stress. ${ }^{[101]}$ A broad variety of seeds including crop plants have been stimulated to germinate by treatment of these phytoene desaturase inhibitors. However, some seed species displayed much lower sensitivity towards these compounds and, in some cases, the synergy with gibberellin or light successfully overcame dormancy and increased seed germination. ${ }^{[93 a, 101,102]}$

There is a clear need to identify more specific ABA biosynthesis inhibitors compared to the phytoene desaturase inhibitors. In the biosynthetic pathway of ABA, the 9-cis-epoxycarotenoid dioxygenase (NCED), which catalyses the rate limit-

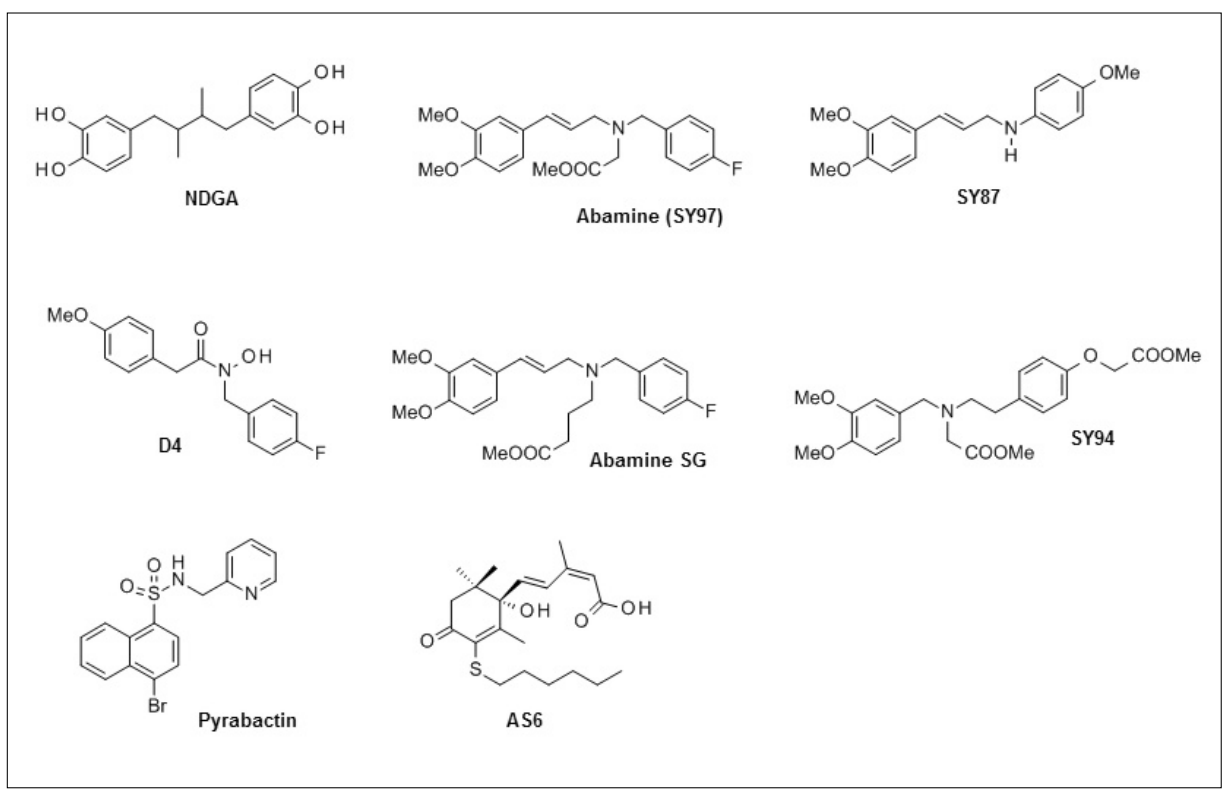

Fig. 11. Compounds used to decrease ABA level through NCED inhibition and compounds mimicking or antagonising the perception of ABA.

ing step of cleavage of an olefinic double bond of 9-cis-neoxanthin into xanthoxin is a very attractive downstream target. However, NCED is a member of the carotenoid-cleaving dioxygenases which are involved in several biosynthetic pathways, for example that of the strigolactones. Therefore, the inhibition of NCED should be selective to reduce the level of ABA in seed and stimulate germination without interfering with other biosynthetic pathways. ${ }^{97,103]}$

The starting point for the development of the NCED inhibitors was the identification of nordihydroguaiaretic acid (NDGA, Fig. 11), a lipoxygenase inhibitor which decreases $\mathrm{ABA}$ levels in treated plants by inhibition of NCED. [103] Although NDGA itself showed no beneficial effect on seed germination, it stimulated the search for improved derivatives. ${ }^{[104]}$ These studies led to the design of NDGA analogues having an amine residue in the linker between both aromatic rings as for example abamine and abamine analogues (Fig. 11), which displays stimulating effect on seed germination. [104d] More recently, derivatives with a hydroxamic acid as linker between two substituted phenyl rings as NCED inhibitors have been described. [105] However, the hydroxamic acid derivatives are not targeting specifically NCED butalso other carotenoid-cleaving dioxygenases (CCDs) which are involved, for example, in the biosynthetic pathway of strigolactones. Therefore, the selectivity of inhibition of the hydroxamic acid derivatives as D4 to reduce the level of $\mathrm{ABA}$ in seeds has to be optimised.

Recently, significant progress has been made in the understanding of ABAsignalling at the molecular level. ABA

\section{.} low temperature, could offer important economic benefits. Despite the large efforts made to identify chemicals displaying strong seed germination induction properties, there are, so far, only relatively few classes of compounds that were shown to be effective on a variety of seed species. Most of the seed germination stimulation compounds act on the biosynthesis and/or on the signalling of phytohormones or are themselves agonists or antagonists of these hormones. Moreover, the recent progresses made at the molecular level in the mechanisms of the mode of action of the phytohormones and on their cross-talks allow the design of more potent and more specific synthetic analogues. Until 2008, a major player in the 'phytohormones orchestra' remained unidentified, namely the strigolactones. The recent data disclosed on strigolactones and on karrikins and their interactions with the other phytohormones provide very promising research opportunities which 
could lead ultimately to derivatives able to stimulate specifically the germination of seeds and the subsequent development steps of the resulting plants.

\section{Acknowledgments}

We would like to thank Chris Godfrey (Syngenta) for his careful review of the manuscript and for his valuable suggestions and corrections.

Received: July 29, 2014

[1] http://faostat.fao.org/site/567/default. aspx\#ancor last access: 23/12/2013.

[2] L. O. Copeland, M. B. McDonald, 'Principles of seed science and technology', 2001, $4^{\text {th }}$ ed. Kluwer Academic Pub.

[3] a) D. M. TeKrony, D. B. Egli, Crop Sci. 1991, 31, 816; b) R. H. Ellis, Plant Growth Regul. 1992, 11, 249; c) D. B. Egli, M. Rucker. Crop Sci. 2012, 52, 2774.

[4] a) L. Rajjou, M. Duval, K. Gallardo, J. Catusse, J. Bally, C. Job, D. Job, Annu. Rev. Plant Biol. 2012, 63, 507; b) G. W. Bassel, H. Lan, E. Glaab, D. J. Gibbs, T. Gerjets, N. Krasnogor, A. J. Bonner, M. J. Holdsworth, N. J. Provart, Proc. Natl. Acad. Sci. USA 2011, 108, 9709; c) M. J. Holdsworth, L. Bentsink, W. J. J. Soppe, New Phytol. 2008, 179, 33; d) M. Miransari, D. L. Smith, Environ. Exp. Bot. 2014, 99, 110.

[5] a) J. D. Bewley, K. J. Bradford, H. W. M. Hilhorst, H. Nonogaki, 'Seeds: Physiology of Development, Germination and Dormancy', 2013, 3rd Ed. Springer Science and Business Media; b) K. P. Lee, U. Piskurewicz, V. Tureckova, M. Strnad, L. Lopez-Molina, Proc. Natl. Acad. Sci. USA 2010, 107, 19108.

[6] a) W. E. Finch-Savage, G. Leubner-Metzger, New Phytol. 2006, 171, 501; b) C. S. C Cadman, P. E Toorop, H. W. M. Hilhorst, W. E. Finch-Savage, Plant J. 2006, 46, 805; c) U. Piskurewicz, V. Tureckova, E. Lacombe, L. Lopez-Molina, EMBO J. 2009, 28, 2259.

[7] K. Weitbrecht, K. Müller, G. Leubner-Metzger, J. Exp. Bot. 2011, 62, 3289.

[8] a) H. Nonogaki, F. Chen, K. J. Bradford, 'Seed Development, Dormancy and Germination', 2007, Ed. Blackwell Publishing Ltd.; b) E. Arc, M. Galland, G. Cueff, B. Godin, I. Lounifi, D. Job, L. Rajjou, Proteomics 2011, 11, 1606.

[9] M. J. Holdsworth, W. E. Finch-Savage, P. Grappin, D. Job, Trends Plant Sci. 2008, 13, 7. See also references [11] $\mathrm{c}$ and [11] d.

[10] a) M. d. C. Rodriguez-Gacio, M. A. MatillaVazquez, A. J. Matilla, Plant Sign. Behav. 2009, 4, 1035; b) Y. Liu, N. Ye, R. Liu, M. Chen, J. Zhang, J. Exp. Bot. 2010, 61, 2979; c) S. Toh; Y. Kamiya, N. Kawakami, E. Nambara, P. McCourt, Y. Tsuchiya, Plant Cell Physiol. 2012, 53. 107.

[11] a) B. B. Stowe, T. Yamaki, Science 1959, 129, 807; b) L. N. Mander, Nat. Prod. Rep. 2003, 20 , 49; c) R. W. King, L. T. Evans, Annu. Rev. Plant Biol. 2003, 54, 307; d) B. Kurcera, M. A. Cohn, G. Leubner-Metzger, Seed Sci. Res. 2005, 15, 281; e) R. Finkelstein, W. Reeves, T. Ariizumi, C. Steber, Annu. Rev. Plant Bio. 2008, 59, 387; f) P. Diaz-Vivancos, G. Barba-Espín, J. A. Hernández, Plant Cell Rep. 2013, 32, 1491.

[12] S. G. Thomas, I. Rieu, C. M. Steber, Vitam. Horm. 2005, 72, 289.

[13] M. Ueguchi-Tanaka, M. Ashikari, M. Nakajima, H. Itoh, E. Katoh, Nature 2005, 437, 693.

[14] a) E. Nambara, A. Marion-Poll, Trends Plant Sci. 2003, 8, 213; b) A. R. Kermode, J. Plant Growth Regul. 2005, 24, 319.

[15] a) Y. Kamiya, J. L. Garcia-Martinez, Curn Opinion Plant Biol. 1999, 2, 398; b) S.
Yamaguchi, Y. Kamiya, T. P. Sun, Plant J. 2001, 28,443 .

[16] a) M. Ogawa, A. Hanada, Y. Yamauchi, A. Kuwahara,Y. Kamiya, S. Yamaguchi, Plant Cell 2003, 15, 1591; b) Y. Yamauchi, M. Ogawa, A. Kuwahara, A. Hanada,Y. Kamiya, S. Yamaguchi, Plant Cell 2004, 16, 367.

[17] a) M. Koornneef, L. Bentsink, H. Hilhorst, Curr. Opinion Plant Biol. 2002, 5, 33; b) G. Leubner-Metzger, Seed Sci. Res. 2003, 13, 17.

[18] D. E. Richards, K. E. King, T. Aitali, N. P. Harberd, Annu. Rev. Plant Physiol. Plant Mol. Biol. 2001, 52, 67.

[19] S. Yamaguchi, Y. Kamiya, J. Plant Growth Regul. 2002, 20, 369.

[20] K. Nakaminami, Y. Sawada, M. Suzuki, H. Kenmoku, H. Kawaide, W. Mitsuhashi, T. Sassa, Y. Inoue, Y. Kamiya, T. Tomoyasu, Biosci. Biotech. Biochem. 2003, 67, 1551.

[21] a) T. Ariizumi, C. M. Steber, Plant Cell 2007, 19, 791; b) L. Tyler, S. G. Thomas, J. Hu. A. Dill, J. M. Alonso, J. E. Ecker, T. Sun Plant Physiol. 2004, 135, 1008

[22] a) K. Murase, Y. Hirano, T. Sun, T. Hakoshima, Nature 2008, 456, 459; b) A. Shimada, M. Ueguchi-Tanaka. T. Nakatsu, M. Nakajima, Y. Naoe, H. Ohmiya, H. Kato, M. Matsuoka, Nature 2008, 456, 520

[23] J. M. Metzger, Weed Sci. 1983, 31, 285.24.

[24] a) R. Bogatek, A. Gniazdowska, Ann. Plant. Rev. 2012, 44, 189; b) A. Linkies, G. LeubnerMetzger, Plant Cell Rep. 2012, 31, 253.

[25] C. A. McClellan, C. Chang, Plant Sci. 2008, $175,24$.

[26] K. L.-C. Wang, H. Li, J. R. Ecker, Plant Cell 2002, 14, S131.

[27] A. J. Matilla, M. A. Matilla-Vazquez, Plant Sci. 2008, $175,87$.

[28] M. Ghassemian, E. Nambara, S. Cutler, H. Kawaide, Y. Kamiya, P. McCourt, Plant Cell 2000, 12,1117

[29] Z. Lin, S. Zhong, D. Grierson, J. Exp. Bot. 2009, 60, 3311

[30] a) W. M. Nascimento, D. J. Cantliffe, D. J. Huber, J. Am. Soc. Hortic. Sci. 2000, 125, 518; b) M. Gallardo, I. Sanchez-Calle, P. Munoz De Rueda, A. J. Matilla, Aust. J. Plant Physiol. 1996, $23,479$.

[31] S. Toh, A. Imamura, A. Watanabe, K. Nakabayashi, M. Okamoto,Y. Jikumaru, A. Hanada, Y. Aso, K. Ishiyama, N. Tamura, S. Iuchi, M. Kobayashi, S. Yamaguchi, Y. Kamiya, E. Nambara, N. Kawakami, Plant Physiol. 2008, 146, 1368

[32] A. P. Calvo, C. Nicolas, G. Nicolas, D. Rodriguez, Phys. Plantarum 2004, 120, 623.

[33] C. E. Cook, L. P. Whichard, B. Turner, M. E. Wall, G. H. Egley, Science 1966, 154, 1189.

[34] a) A. W. Johnson, G. Gowda, A. Hassanali, J. Knox, S. Monaco, Z. Razavi, G. Rosebery, J. Chem. Soc. Perkin Trans. I 1981, 1734; b) M. Lachia, P. M. J. Jung, A. De Mesmaeker, Tetrahedron Lett. 2012, 53, 4514. c) M. Lachia, H. C. Wolf, A. De Mesmaeker, Bioorg. Med. Chem. Lett. 2014, 24, 2123.

[35] J. Willem, J. F. Thuring, A. A. M. A. van Gaal, S. J. Hornes, M. M. de Kok, G. H. L. Nefkens, B. Zwanenburg, J. Chem. Soc. Perkin Trans. I 1997, 767.

[36] A. S. Mwakaboko, B. Zwanenburg, Plant Cell Physiol. 2011, 52, 699.

[37] B. Zwanenburg, A. S. Mwakaboko, Bioorg. Med. Chem. 2011, 19, 7394.

[38] B. Zwanenburg, A. S. Mwakaboko, A. Reizelman, G. Anilkumar, D. Sethumadhavan, Pest. Manag. Sci. 2009, 65, 478

[39] A. G. T. Babiker, A. M. Hamdoun, A. Rudwan, N. G. Mansi, H. H. Faki, Weed Res. 1987, 27, 173.

[40] a) J. M. Bradow, W. Connick, A. B. Pepperman, J. Plant Growth Regul. 1988, 7, 227; b) J. M. Bradow, W. J. Connick, A. B. Pepperman, L. H.
Wartelle, J. Plant Growth Regul. 1990, 9, 35

[41] M.-M. Lechat, J.-B. Pouvreau, T. Péron, M. Gauthier, G. Montiel, C. Véronési, Y. Todokori, B. Le Bizec, F. Monteau, D. Macherel, P. Simier, S. Thoiron, P. Delavault, J. Exp. Bot. 2012, 63, 5311 .

[42] a) K. Akiyama, K. Matsuzaki, H. Hayashi, Nature 2005, 435, 824; b) K. Akiyama,S. Ogasawara, S. Ito, H. Hayashi, Plant Cell Physiol. 2010, 51, 1104.

[43] a) V. Gomez-Roldan, S. Fermas, P. B. Brewer, V. Puech-Pagès, E. A. Dun, J.-P. Pillot, F. Letisse, R. Matusova, S. Danoun, J.-C. Portais, H. Bouwmeester, G. Bécard, C. A. Beveridge, C. Rameau, S. F. Rochange, Nature, 2008, 455, 189; b) M. Umehara, A. Hanada, S. Yoshida, K. Akiyama, T. Arite, N. Takeda-Kamiya, H. Magome, Y. Kamiya, K. Shirasu, K. Yoneyama, J. Kyozuka, S. Yamaguchi, Nature, 2008, 455, 195.

[44] C. Ruyter-Spira, W. Kohlen, T. Charnikhova, A. Van Zeijl, L. Van Bezouwen, N. De Ruijter, C. Cardoso, J. A. Lopez-Raez, R. Matusova, R. Bours, F. Verstappen, H. Bouwmeester, Plant Physiol. 2011, 155, 721.

[45] a) B. J. Janssen, K. C. Snowden, Front. Plant Sci. 2012, 3, 296; b) M. Kagiyama, Y. Hirano, T. Mori, S. Kim, J. Kyozuka, Y. Seto, S. Yamaguchi, T. Hakoshima, Genes Cell, 2013, 147; c) R. Bythell-Douglas, M. T. Waters, A. Scaffidi, G. R. Flematti, S. M. Smith, C. S. Bond, PLoS One, 2013, 8, e54758; d) L. Zhao, X. E. Zhou, Z. Wu, W. Yei, Y. Xu, S. Li, T. Xu, Y. Liu, R. Chen, A. Kovach, Y. Kang, L. Hou, Y. He, C. Xie, W. Song, D. Zhong, Y. Xu, Y. Wang, J. Li, C. Zhang, K. Melcher, H. E. Xu, Cell Res. 2013, 23, 436; e) M. T. Waters, S. M. Smith, Mol. Plant 2013, 6, 63; f) Y. Guo, Z. Zheng, J. J. La Clair, J. Chory, J. P. Noel, Proc. Natl. Acad. Sci. USA 2013, 110, 8284

[46] a) H. Nakamura, Y. Xue, T. Miyaka, F. Hou, H. Qin, K. Fukui, X. Shi, E. Ito, S. Ito, S. Park, Y. Miyauchi, A. Asano, N. Totsuka, T. Ueda, M. Tanakura, T. Asami, Nature Commun. 2013, 4, 2613; b) F. Zhou, Q. Lin, L. Zhu, Y. Ren, K. Zhou, N. Shabek, F. Wu, H. Mao, W. Dong, L. Gan, W. Ma, H. Gao, J. Chen, C. Yang, D. Wang, J. Tan, X. Zhang, X. Guo, J. Wang, L. Jiang, X. Liu, W. Chen, J. Chu, C. Yan, K. Ueno, S. Ito, T. Asami, Z. Cheng, J. Wang, C. Lei, H. Zhai, C. Wu, H. Wang, N. Zheng, J. Wan, Nature 2013, $504,406$.

[47] a) J. H. De Lange, C. Boucher, S. Afr. J. Bot. 1990, 162, 507; b) N. A. C. Brown, New Phytol. 1993, 123,575 ; c) I. T. Baldwin, L. Morse, $J$. Chem. Ecol. 1994, 20, 2373.

[48] a) N. A. C. Brown, S. Afr. J. Bot. 2004, 70, 559; b) S. Roche, K. W. Dixon, J. S. Pate, Aust. J. Bot. 1997, 45, 783; c) J. E. Keeley, C. J. Fotheringham, Ecology, 1998, 79, 2320.

[49] a) G. R. Flematti, E. D. Goddard-Borger, D. J. Merritt, E. L. Ghisalberti, K. W. Dixon, R. D. Trengove, J. Agric. Food Chem. 2007, 55, 2189; b) S. D. S. Chiwocha, K. W. Dixon, G. R. Flematti, E. L. Ghisalberti, D. J. Merritt, D. C. Nelson, J.-A. M. Riseborough, S. M. Smith, J. C. Stevens, Plant Sci. 2009, 177, 252; c) M. E. Light, M. I. Van Staden, S. Afr. J. Bot. 2009, 75,1 ; d) D. C. Nelson, G. R. Flematti, E. L. Ghisalberti, K. W. Dixon, S. M. Smith, Аnпи. Rev. Plant Biol. 2012, 63, 107.

[50] K. W. Dixon, D. J. Merritt, G. R. Flematti, E. L. Ghisalberti, Acta Hort. 2009, 813, 155.

[51] M. E. Light, B. V. Burger, D. Staerk, L. Kohout, J. Van Staden, J. Nat. Prod. 2010, 73, 267.

[52] M. G. Kulkarni, G. D. Ascough, L. Verschaeve, K. Baeten, M. P. Arruda, J. Van Staden, Sc. Hortic. 2010, 124, 434.

[53] a) G. R. Flematti, E. L. Ghisalberti, K. W. Dixon, R. D. Trengove, Science 2004, 305, 977; b) J. Van Staden, A. K. Jäger, M. E. Light, B. V. Burger, S. Afr. J. Bot. 2004, 70, 654. 
[54] G. R. Flematti, A. Scaffidi, E. D. GoddardBorger, C. H. Heath. D. C. Nelson, L. E. Commander, R. V. Stick, K. W. Dixon, S. M. Smith, E. L Ghisalberti, J. Agric. Food Chem. 2010, 58,8612 .

[55] a) M. G. Kulkarni, S. G. Sparg, M. E. Light, J. Van Staden, J. Agro. Crop Sci. 2006, 192, 395 b) J. Van Staden, S. G. Sparg, M. G. Kulkarni, M. E. Light, Field Crop Res. 2006, 98, 98; c) M. G. Kulkarni, G. D. Ascough, J. Van Staden, Hort. Sci. 2007, 42, 179

[56] M. I. Daws, J. Davies, H. W. Pritchard, N. A C. Brown, J. Van Staden, Plant Growth. Regul. 2007, 51, 73 .

[57] N. Jain, M. G. Kulkarni, J. Van Staden, Plant Growth Regul. 2006, 49, 263

[58] a) A. Scaffidi, M. T. Waters. C. S. Bond, K. W. Dixon, S. M. Smith, E. L. Ghisalberti, G R. Flematti, Bioorg. Med. Chem. Lett. 2012 22, 3743; b) M. T. Waters, A. Scaffidi, G. R. Flematti, S. M. Smith, Plant Sign. Behav. 2012 7,969.

[59] M. T. Waters, D. C. Nelson, A. Scaffidi, G. R. Flematti, Y. K. Sun. K. W. Dixon, S. M. Smith Develop. 2012, 139, 1285.

[60] M. D. Grove, G. F. Spencer, W. K. Rohwedder, N. Mandava, J. F. Worley, J. D. Warthen, G. L. Steffens, J. L. Flippen-Anderson, J. C. Cook, Nature 1979, 281, 216

[61] T. G. Back, R. P. Pharis, J. Plant Growth Regul. 2003, 22, 350

[62] a) M. Hothorn, Y. Belkhadir, M. Dreux, T. Dabi, J. P. Noel, I. A. Wilson, J. Chory, Nature 2011 474, 467; b) J. She, Z. Han, T.-W. Kim, J. Wang, W. Cheng, J. Chang, S. Shi, J. Wang, M. Yang, Z.-Y. Wang, J. Chai, Nature 2011, 474, 472; c) J. She, Z. Han, B. Zhou, J. Chai, Protein Cell 2013, 4, 475; d) J. Santiago, C. Henzler, M. Hothorn, Science 2013, 341, 889 .

[63] a) T. C. McMorris, P. A. Patil, J. Org. Chem 1993, 58, 2338; b) W.-S. Zhou, Y.-P. Zhou, B. Jiang, Synthesis 1989, 426; c) C. Brosa, Steroids 1994, 59, 463; d) M. Sakakibara, K. Okada, Y. Ichikawa, K. Mori, Heterocycles 1982, 17, 301.

[64] a) P. Krishna, J. Plant Growth Regul. 2003, 22 289; b) B. V. Vardhini, S. Anuradha, S. R. Rao, Indian J. Plant Physiol. 2006, 11, 1

[65] a) V. Khripach, V. Zhabinskii, A. De Groot, Ann. Bot. 2000, 86, 44 b) M. A. T. Zullo, G. Adam, Braz. J. Plant Physiol. 2002, 14, 143.

[66] B. Vidya, S. Vardhini, S. Seeta Ram Rao, Indian J. Plant Physiol. 2005, 10, 381.

[67] a) N. Arora, R. Bhardwaj, P. Sharma, H. Kumar Arora, Acta Physiol. Planta 2008, 30, 833; b) S. Anuradha, S. Seeta Ram Rao, Plant Growth Regul. 2003, 40, 29; c) F. Özdemir, M. Bor, T. Demiral, I. Türkan, Plant Growth Regul. 2004 42, 203; d) S. Kagale, U.K. Divi, J. E. Krochko, W. A. Keller, P. Krishna, Planta 2007, 225, 353.

[68] T. Nomura, M. Ueno, Y. Yamada, S. Takatsuto, Y. Takeuchi, T. Yokota, Plant Physiol. 2007, 143,1680

[69] Y. Takeuchi, Y. Omigawa, M. Ogasawara, K Yoneyama, M. Konnai, A. D. Worsham Plant Growth Regul. 1995, 16, 153

[70] a) C. Müssig, S. Fischer, T. Altmann, Plant Physiol. 2002, 129, 1241; b) H. Goda, Y. Shimada, T. Asami, S. Fujioka, S. Yoshida, Plant Physiol. 2002, 130, 1319.

[71] S. D. Clouse, J. M. Sasse, Annu. Rev. Plant Physiol. Plant Mol. Biol. 1998, 49, 427.

[72] a) C. M. Steber, P. McCourt, Plant Physiol. 2001, 125, 763; b) L.-W. Xue, J.-B. Du, H. Yang, F. Xu, S. Yuan, H.-H. Lin, Z. Naturforsch. 2009, 64c, 225.

[73] a) T. Schmülling in 'Encyclopedia of Biological Chemistry', Eds. W. Lennarz, M. D. Lane, Academic Press/Elsevier Science, 2004, p.1; b) H. Sabakibara, Annu. Rev. Plant Biol. 2006, 57 , 431 ; c) T. Werner, T. Schmülling, Curr. Opin. Plant. Biol. 2009, 12, 527; d) M. Hothorn, T. Dabi, J. Chory, Nat. Chem. Biol. 2011, 7, 766.
[74] A. Kunikowska, A. Byczkowska, M. Doniak, A. Kazmierczak, Plant Cell Rep. 2013, 32, 771.

[75] S. Gan, R. M. Amasino, BioEssays 1996, 18, 557.

[76] a) C. O. Miller, F. Skoog, F. S. Okumura, J. Am Chem. Soc. 1956, 78, 1375; b) M. Koorneef, C. M. Karssen in 'Arabidopsis', Eds. E. M. Meyerowitz, C. R. Somerville, Cold Spring Harbor Laboratory Press, Cold Spring Harbor, New York, 1994, p. 313.

[77] a) A. A. Khan, Nature, 1967, 216, 166; b) A. A. Khan, Plant Physiol. 1968, 43, 1463; c) A. A. Khan, Science 1971, 171, 853.

[78] J. R. Dunlap, P. W. Morgan, Plant Physiol. 1977, 60, 222.

[79] M. Riefler, O. Novak, M. Strnad, T. Schmülling, Plant Cell, 2006, 18, 40 .

[80] L. Spíchal, T. Werner, I. Popa, M. Riefler, T. Schmülling, FEBS J. 2009, 276, 244.

[81] J. Nisler, M. Zatloukal, I. Popa, K. Dolezal, M. Strnad, L. Spichal, Phytochem. 2010, 71, 823.

82] Y. Wang, L. Li, T. Ye, S. Zhao, Z. Liu, Y.-Q. Feng, Y. Wu, Plant J. 2011, 68, 249.

[83] a) T. H. Thomas, Ann. Appl. Biol. 1974, 76, 237; b) H. Iwamura, N. Masuda, K. Koshimizu, S. Matsubara, Phytochem. 1979, 18, 217.

[84] W. J. Pietraface, D. F. Blayes, Physiol. Plant. 1981, 53, 249.

[85] a) N. P. Kefford, J. A. Zwar, M. I. Bruce, Planta, 1965, 67, 103.; b) M. I. Bruce, J. A. Zwar, N. P. Kefford, Life Sci. 1965, 4, 461.

[86] G. Noctor, C. H. Foyer, Annu. Rev. Plant Physiol. Plant Mol. Biol. 1998, 49, 249.

[87] M. M. Azooz, M. A. Al-Fredan, Am. J. Plant Physiol. 2009, 4, 38

[88] R. T. Behairy, M. El-Danasoury, L. Craker, $J$. Med. Act. Plants 2012, 1, 106.

[89] N. Smirnoff, G. L. Wheeler, Crit. Rev. Biochem. Mol. Biol. 2000, 35, 291

[90] a) J. J. Smith, P. Ververidis, P. John, Phytochem 1992, 31, 1485; b) N. Ye, J. Zhang, Plant Sign. Behav. 2012, 7, 563 .

[91] P. C. Bethke, I. G. L. Libourel, V. Reinöhl, R. L. Jones, Planta 2006, 223, 805.

[92] P. C. Bethke, I. G. L. Libourel, N. Aoyama, Y.-Y. Chung, D. W. Still, R. L. Jones, Plant Physiol. 2007, 143, 1173.

[93] a) S. Ali-Rachedi, D. Bouinot, M.- H. Wagner, M. Bonnet, B. Sotta, P. Grappin, M. Jullien, Planta 2004, 219, 479; b) A. Alboresi, C. Gestin, M.-T. Leydecker, M. Bedu, C. Meyer, H.-N. Truong, Plant Cell Environ. 2005, 28, 500.

[94] Y. Esashi, K. Isuzugawa, S. Matsuyama, H Ashino, R. Hasegawa, Physiol. Planta. 1991, $83,27$.

95] a) R. Bogatek, S. Lewak, Physiol. Planta. 1991 83,422 ; b) P. C. Bethke, I. G. L. Libourel, R. L. Jones, J. Exp. Bot. 2006, 57, 517

[96] G. R. Flematti, D. J. Merritt, M. J. Piggott, R D. Trengove, S. M. Smith, K. W. Dixon, E. L. Ghisalberti, Nature Commun. 2011, 2, 360.

97] a) K. Graeber, K. Nakabayashi, E. Miatton, G. Leubner-Metzger, W. J. J. Soppe, Plant, Cell Environ. 2012, 35, 1769; b) A. J. Matilla, F. de la Torre, R. Iglesias-Fernandez, Curr. Topics Phytochem. 2007, 8, 59.

[98] N. Kitahata, T. Asami, J. Plant Res. 2011, 124, 549.

[99] P. G. Bartels, C. W. Watson, Weed Sci. 1978, 26, 198.

[100] G. Hamprecht, M. Witschel, in 'Modern Crop Protection Compounds', Eds. W. Krämer, U. Schirmer, Wiley-VCH, 2007, 1, 187.

[101] a) J. Leymarie, M. E. Robayo-Romero, E. Gendreau, R. L. Benech-Arnold, F. Corbineau, Plant Cell Physiol. 2008, 49, 183; b) T. Yoshioka, T. Endo, S. Satoh, Plant Cell Physiol. 1998, 39, 307; c) W. Zhang, L. V. Gusta, Plant Growth Regul. 2010, 60, 105; d ) M. Fellner, V. K. Sawhney, Theor. Appl. Gen. 2001, 102, 215 e) A. Atia, A. Debez, Z. Barhoumi, A. Smaoui,
C. Abdelly, C. R. Biol. 2009, 332, 704; f) K.-O. Widell, C. Sundqvist, H. I. Virgin, Weed Sci. 1985, 33, 160; g) K. Mitrakos, K. Georghiou, G. Psaras, J. Plant Physiol. 1985, 119, 201.

[102] a) D. J. Hole, J. D. Smith, B. G. Cobb, Plant Physiol. 1989, 91, 101; b) M. Y. Oishi, J. D. Bewley, J. Exp. Bot. 1992, 43, 759; c) H. S. Steinbach, R. L. Benech-Arnold, R. A Sanchez, Plant Physiol. 1997, 113, 149; d) R. L. Benech-Arnold, S. Enciso, R. A. Sanchez, M. V. Rodriguez, New Phytol. 2003, 160, 371; e) J. Bianco, G. Garello, M. T. Le Page-Degivry, Seed Sci. Res. 1994, 4, 57; f) G. Garello, M. T. Le Page-Degivry, Seed Sci. Res. 1999, 9, 219; g) A. Gianinetti, P. Vernieri, J. Exp. Bot. 2007, 58, 3449; h) J. A. Feurtado, J. Yang, S. J. Ambrose, A. J. Cutler, S. R. Abrams, A. R. Kermode, J. Plant Growth Regul. 2007, 26, 46; i) T. Gonai, S. Kawahara, M. Tougou, S. Satoh, T. Hashiba, N. Hirai, H. Kawaide, Y. Kamiya, T. Yoshioka, J. Exp. Bot. 2004, 55, 111.

103] R. A. Creelman, E. Bell, J. E. Mullet, Plant Physiol. 1992, 99, 1258.

[104] a) N. Kitahata, S. Ito, A. Kato, K. Ueno, T. Nakano, K. Yoneyama, K. Yonemana, T. Asami, J. Pest. Sci. 2011, 36, 53; b) S.-Y. Han, N. Kitahata, T. Saito, M. Kobayashi, K. Shinozaki, S. Yoshida, T. Asami, Bioorg. Med. Chem. Lett. 2004, 14, 3033; c) S.-Y. Han, N. Kitahata, K. Sekimata, T. Saito, M. Kobayashi, K. Nakashima, K. Yamaguchi-Shinozaki, K. Shinozaki, S. Yoshida, T. Asami, Plant Physiol. 2004, 135, 1574; d) S. Yoshida, T. Asami, WO Patent Appl. No. 2003031389, 2003 (US 7098365); e) G. Zhu, N. Ye, J. Zhang, Plant Cell Physiol. 2009, 50, 644; f) S. D. Elakovich, K. L. Stevens, J. Chem. Ecol. 1985, 11, 27; g) G. Gao, S. Zhang, C. Wang, X. Yang, Y. Wang, $\mathrm{X}$. Su, J. Du, C Yang, PLoS One 2011, 6 , e19406; h) N. Kitahata, S.-Y. Han, N. Noji, T. Saito, M. Kobayashi, T. Nakano, K. Kuchitsu, K. Shinozaki, S. Yoshida, S. Matsumoto, M. Tsujimoto, T. Asami, Bioorg. Med. Chem. 2006, 14,5555 .

[105] a) M. J. Sergeant, J.-J. Li, C. Fox, N. Brookbank, D. Rea, T. D. H. Bugg, A. J Thompson, J. Biol. Chem. 2009, 284, 5257; b) A. Thompson, T. Bugg, WO Patent Appl. No. 2010055316, 2010

[106] a) J. Santiago, F. Dupeux, A. Round, R. Antoni, S.-Y. Park, M. Jamin, S. R. Cutler, P. L. Rodriguez, J. A. Márquez, Nature 2009, 462, 665 ; b) F. C. Peterson, E. S. Burgie, S.-Y. Park, D. R. Jensen, J. J. Weiner, C. A. Bingman, C.E. A. Chang, S. R. Cutler, G. N. Phillips Jr., B. F. Volkman, Nat. Struct. Mol. Biol. 2010, 17,1109 ; c) M. Nakagawa, M. Kagiyama, N. Shibata, Y. Hirano, T. Hakoshima Genes Cell 2014, 19, 386

[107] K. Melcher, Y. Xu, L. M. Ng, X. E. Zhou, F.-F. Soon, V. Chinnusamy, K. M. Suino-Powell, A. Kovach, F. S. Tham, S. R. Cutler, J. Li, E.-L. Yong, J.-K. Zhu, H. E. Xu Nat. Struct. Mol. Biol. 2010, 17, 1102.

[108] J. Takeuchi, M. Okamoto, T. Akiyama, T. Muto, S. Yajima, M. Sue, M. Seo, Y. Kanno, T. Kamo, A. Endo, E. Nambara, N. Hirai, T. Ohnishi, S. R. Cutler, Y. Todoroki, Nat. Chem. Biol. 2014, 10, 477. 